\title{
$1 \quad$ Testing theoretical minimal genomes using whole-cell models
} combined with its long replication time of 12 - 15 hours, none of these theoretical minimal

20

21 W

designs created using the currently incomplete and fragmented gene essentiality information,

Joshua Rees-Garbutt ${ }^{1,2^{*}}$, Jake Rightmyer ${ }^{2}$, Oliver Chalkley ${ }^{1,3,4}$, Lucia Marucci ${ }^{1,4,5}+^{*}$, Claire Grierson ${ }^{1,2 t^{*}}$

1. BrisSynBio, University of Bristol, Bristol BS8 1TQ, UK;

2. School of Biological Sciences, University of Bristol, Bristol Life Sciences Building, 24 Tyndall Avenue, Bristol, BS8 1TQ, UK;

3. Bristol Centre for Complexity Sciences, Department of Engineering Mathematics, University of Bristol, Bristol, BS8 1UB, UK

4. Department of Engineering Mathematics, University of Bristol, Bristol BS8 1UB, UK;

5. School of Cellular and Molecular Medicine, University of Bristol, Bristol BS8 1UB, UK;

+ Co-last authors * Corresponding authors

Co-Corresponding authors: Joshua Rees-Garbutt, Prof. Claire Grierson, Dr. Lucia Marucci Email: joshua.rees@bristol.ac.uk, lucia.marucci@bristol.ac.uk, lacsg@bristol.ac.uk

\section{Abstract}

The minimal gene set for life has often been theorised, with at least ten produced for

Mycoplasma genitalium (M. genitalium). Due to the difficulty of using M. genitalium in the lab, genomes have been tested, even with modern techniques. The publication of the M. genitalium

whole-cell model provided the first opportunity to test them, simulating the genome edits

in-silico. We simulated eight minimal gene sets from the literature, finding that they produced

in-silico cells that did not divide. Using knowledge from previous research, we reintroduced specific essential and low essential genes in-silico; enabling cellular division. This reinforces the

need to identify species-specific low essential genes and their interactions. Any genome

will very likely require in-vivo reintroductions to correct issues and produce dividing cells. 


\section{Introduction}

31 Genome engineering builds on historical gene essentiality research. The sequencing of small

32 bacterial genomes (Fleischmann et al., 1995; Fraser et al., 1995) led to comparative genomics;

33 then, as genome sequences completed increased, minimal gene sets (Forster \& Church, 2006;

34 R. Gil et al., 2004; Rosario Gil, 2015; J. I. Glass et al., 2006; Huang et al., 2013; Hutchison et

35 al., 1999; Karr et al., 2012; Mushegian \& Koonin, 1996; Shuler et al., 2012; Tomita et al., 1999)

36 were hypothesised. Minimal genomes are reduced genomes where no single gene can be

37 removed without loss of reproduction (John I. Glass et al., 2017), given an appropriately rich

38 medium and no external stresses, and focusing solely on protein-coding genes. For a recent

39 review of gene essentiality, see Rancati et al. (Rancati et al., 2018).

40

$41 \mathrm{M}$. genitalium is the focal point of minimal gene set creation due its naturally small genome size

42 (0.58mb and 525 genes) and early sequenced genome (Fraser et al., 1995). Minimal gene sets

43 are designed using three different approaches: protocells, comparative genomics, and single

44 gene knockouts. Protocell designs (Dzieciol \& Mann, 2012) are not expected to function as true

45 biological cells, instead functioning as a self-replicating, membrane-encapsulated collection of

46 biomolecules (Forster \& Church, 2006). Comparative genomics (Koonin, 2003) compares

47 multiple species to identify common genes. This is complicated (John I. Glass et al., 2017;

48 Lagesen et al., 2010) by non-orthologous gene displacements, i.e. independently evolved or

49 diverged proteins that perform the same function but are not recognisably related (John I. Glass

50 et al., 2017; Mushegian \& Koonin, 1996), which can result in the removal of a large number of

51 genes essential to one species. Design using single gene essentiality classifications should, in

52 theory, not remove any essential genes; but if transposon mutagenesis is used, variance from

53 different transposon variants, antibiotic resistance genes, and growth periods can result in

54 differing essentiality classifications (J. I. Glass et al., 2006; Juhas et al., 2011). 
55 Ten minimal gene sets were found in the literature that were designed with $M$. genitalium genes

56 (Forster \& Church, 2006; R. Gil et al., 2004; Rosario Gil, 2015; J. I. Glass et al., 2006; Huang et

57 al., 2013; Hutchison et al., 1999; Karr et al., 2012; Mushegian \& Koonin, 1996; Shuler et al.,

58 2012; Tomita et al., 1999). Due to the difficulty of using M. genitalium in the lab (Reich, 2000),

59 combined with its long replication time of 12 - 15 hours (Benders et al., 2010; John I. Glass et

60 al., 2017; Hutchison et al., 2016), none of these theoretical minimal genomes have been tested,

61 even with modern techniques (Benders et al., 2010). The publication of the M. genitalium

62 whole-cell model (Karr et al., 2012) provided the first opportunity to test them, simulating the

63 genome edits in-silico.

64

65 The Mycoplasma genitalium whole-cell model (Karr et al., 2012) was the first existing model of a

66 cell's individual molecules that includes the function of every known gene product (401 of the

67525 M.genitalium genes), making it capable of modelling genes in their genomic context.

68 Previously, it has been used to investigate discrepancies between the model and real-world

69 measurements (Karr et al., 2012; Sanghvi et al., 2013), design synthetic genetic circuits in the

70 context of the cell (Purcell et al., 2013), make predictions about the use of existing antibiotics

71 against new targets (Kazakiewicz et al., 2015), and produce in-silico minimal genomes

72 (Rees-Garbutt et al., 2020).

73

74 Of the ten sets, two of the sets (Gil et al. (2004)(R. Gil et al., 2004)and Shuler et al.(Shuler et al.,

75 2012)) were excluded as they were considered derivative of the Gil (2014) set (Rosario Gil,

76 2015); four genes differ in the Shuler et al. set (MG_056, MG_146, MG_388, MG_391) and four

77 genes are absent in the Gil et al. (2004) set (MG_009, MG_091, MG_132, MG_460). Of the

78 other eight sets, two (Tomita et al. (Tomita et al., 1999) and Church et al. (Forster \& Church,

79 2006)) were designed as protocells, three (Mushegian and Koonin (Mushegian \& Koonin, 1996), 
80 Huang et al. (Huang et al., 2013), and Gil (R. Gil et al., 2004; Rosario Gil, 2015)) from

81 comparative genomics, and three (Hutchison et al. (Hutchison et al., 1999), Glass et al. (J. I.

82 Glass et al., 2006), and Karr et al. (Karr et al., 2012)) from single gene essentiality experiments.

83

84 We simulated eight minimal gene sets from the literature (Forster \& Church, 2006; Rosario Gil,

85 2015; J. I. Glass et al., 2006; Huang et al., 2013; Hutchison et al., 1999; Karr et al., 2012;

86 Mushegian \& Koonin, 1996; Tomita et al., 1999), testing them for the first time. This was to

87 assess their functionality as extant and untested genome designs, but also to produce new

88 data for designing genomes to evaluate the differing approaches of focusing on

89 species-specific data or focusing on identifying core genes and common functions across

90 species.

91

\section{Results}

93 We adapted eight minimal gene sets for simulation within the $M$. genitalium whole-cell model.

94 To increase clarity, we renamed the sets after the main location where the set was constructed

95 (Table 1). The Bethesda set directly compared M. genitalium and Haemophilus influenzae

96 genomes (gram-positive and gram-negative bacteria, respectively) (Mushegian \& Koonin, 1996).

97 The Rockville set applied global transposon mutagenesis to $M$. genitalium in-vivo to identify

98 non-essential genes (Hutchison et al., 1999). The Fujisawa set constructed an in-silico

99 hypothetical cell from 127 M. genitalium genes using the E-Cell software (Tomita et al., 1999).

100 The Rockville 2 set reapplied global transposon mutagenesis in-vivo, isolating and

101 characterising pure clonal populations (J. I. Glass et al., 2006). The Nashville set listed 151

102 E.coli genes (compared to M. genitalium genes within the paper) theorised to produce a

103 chemical system capable of replication and evolution (Forster \& Church, 2006). The Stanford

104 set was the result of in-silico single gene knockouts using the $M$. genitalium whole-cell model 
105 (Karr et al., 2012). The Guelph set compared 186 bacterial genomes (Huang et al., 2013),

106 whereas the Valencia set compared M. genitalium with genetic data of five insect

107 endosymbionts (Rosario Gil, 2015) . The Nashville, Fujisawa, and Stanford sets were

108 unchanged, but the others had between 6 and 44 genes removed (Table 1) either because the

109 genes were unmodelled (the genes' function were unknown (Karr et al., 2012)) or genes had

110 duplicate entries.

112 Table 1. Minimal Gene Sets from the literature.

\begin{tabular}{|c|c|c|c|c|c|c|}
\hline Minimal gene set & $\begin{array}{l}\text { Code } \\
\text { name }\end{array}$ & $\begin{array}{l}\text { Design } \\
\text { approach }\end{array}$ & $\begin{array}{c}\text { In-vivo } \\
\text { genome } \\
\text { design size* }\end{array}$ & $\begin{array}{l}\text { Unmodelled } \\
\text { genes }^{\wedge} \text { in } \\
\text { genome design }\end{array}$ & $\begin{array}{l}\text { Unmodelled } \\
\text { genes^ in gene } \\
\text { deletions }\end{array}$ & $\begin{array}{c}\text { Predicted } \\
\text { in-silico } \\
\text { genome size }\end{array}$ \\
\hline $\begin{array}{l}\text { Forster and Church } 2006 \\
\text { (Forster \& Church, 2006) }\end{array}$ & Nashville & Protocell & 89 & 0 & - & 131 \\
\hline $\begin{array}{l}\text { Tomita et al. 1999 } \\
\text { (Tomita et al., 1999) }\end{array}$ & Fujisawa & Protocell & 98 & 0 & - & 140 \\
\hline $\begin{array}{l}\text { Huang et al. } 2013 \\
\text { (Huang et al., 2013) }\end{array}$ & Guelph & $\begin{array}{c}\text { Comparative } \\
\text { Genomics }\end{array}$ & 123 & 5 & - & 160 \\
\hline $\begin{array}{c}\text { Gil } 2014 \\
\text { (Rosario Gil, 2015) } \\
\end{array}$ & Valencia & $\begin{array}{c}\text { Comparative } \\
\text { Genomics }\end{array}$ & 180 & 6 & - & 216 \\
\hline $\begin{array}{l}\text { Mushegian and Koonin } 1996 \\
\text { (Mushegian \& Koonin, 1996) }\end{array}$ & Bethesda & $\begin{array}{c}\text { Comparative } \\
\text { Genomics }\end{array}$ & 253 & 12 & - & 283 \\
\hline $\begin{array}{c}\text { Karr et al. 2012 } \\
\text { (Karr et al., 2012) }\end{array}$ & Stanford & $\begin{array}{l}\text { Single Gene } \\
\text { Deletions }\end{array}$ & 242 & - & 0 & 284 \\
\hline $\begin{array}{c}\text { Glass et al. } 2006 \\
\text { (J. I. Glass et al., 2006) }\end{array}$ & Rockville 2 & $\begin{array}{l}\text { Single Gene } \\
\text { Deletions }\end{array}$ & 258 & - & 44 & 344 \\
\hline $\begin{array}{l}\text { Hutchison et al. } 1999 \\
\text { (Hutchison et al., 1999) }\end{array}$ & Rockville & $\begin{array}{l}\text { Single Gene } \\
\text { Deletions }\end{array}$ & 265 & - & 41 & 348 \\
\hline- & $\begin{array}{c}\text { M. genitalium } \\
\text { whole-cell } \\
\text { model }^{\star}\end{array}$ & - & 359 & 124 & - & 401 \\
\hline- & $\begin{array}{l}\text { M. genitalium } \\
\text { in-vivo * }\end{array}$ & - & 483 & - & - & 525 \\
\hline
\end{tabular}

113 Comparing minimal gene sets with M. genitalium in-vivo and the M. genitalium whole-cell

114 model. ${ }^{*}=$ protein-coding genes. M. genitalium has 42 RNA-coding genes that are not included

115 in this column, to enable comparison across genome designs. $\wedge=$ due to unknown function.

116 Unmodelled genes in genome design reduces the size of the in-vivo genome design.

117 Unmodelled genes in gene deletions increases the size of the in-vivo genome design.

120 The protocell designs (Nashville, Fujisawa) predicted the smallest in-silico genome. Guelph 
122 species (Huang et al., 2013). Stanford, Rockville, Rockville 2 had similar numbers of in-vivo

123 deletions, but Rockville and Rockville 2 had the highest numbers of unmodelled genes (as

124 genes can be disrupted in-vivo without knowing the gene's function). The in-silico genomes

125 (and associated gene deletions) of the minimal gene sets are listed in Supplementary Data 1

126 and 2.

128 Prior to simulations, we analysed the sets produced by comparative genomics and single gene

129 essentiality and found 96 genes they had in common (Supplementary Data 1 (col L) and 3). We

130 excluded the protocell designs from this comparison due to their much reduced size. 87 of the

131 shared genes were classified as essential (genes that when removed in-silico stopped the cell

132 from dividing, classified in-silico previously (Karr et al., 2012; Rees-Garbutt et al., 2020)), eight

133 were non-essential (removal did not prevent successful cell division), and one gene was

134 unmodelled.

136 The 87 essential genes affect a range of cellular functions including: DNA (repair, supercoiling,

137 chromosome replication, nucleotide synthesis/modification, sigma factors, ligation, transcription

138 termination, and DNA polymerase); RNA (ribosome proteins, translation initiation factors, tRNA

139 modification, ribonucleases, and RNA polymerase); and cellular processes (protein

140 folding/modification, protein shuttling, protein membrane transport, metabolic substrates

141 production/recycling, redox signalling, oxidation stress response, and the pyruvate

142 dehydrogenase complex). Of the eight non-essential genes, four (MG_048, MG_072, MG_170,

143 MG_297) are associated with the SecYEG complex (du Plessis et al., 2011) (protein transport

144 across or into the cell membrane), while MG_172 removes protein synthesis targets from

145 synthesised proteins, MG_305 and MG_392 assist in late protein folding, and MG_425 
146 processes ribosomal RNA precursors. Although these eight genes are singly non-essential (by

147 single gene deletion in-silico (Karr et al., 2012) and in-vivo (J. I. Glass et al., 2006)) they all play

148 a part in essential functions, hence their inclusion.

150 We also identified 14 genes deleted by all eight minimal gene sets (Supplementary Data 2 (col

151 L) and 4). The functions of these genes include: fructose import, host immune response

152 activation, chromosomal partition, amino acid transport, antibody binding, phosphonate

153 transport, external DNA uptake, DNA repair, rRNA modification, membrane breakdown, toxin

154 transport, quorum sensing, and a restriction enzyme. These had been previously classified as

155 non-essential by single gene deletion in-silico (Karr et al., 2012) and in-vivo (J. I. Glass et al.,

156 2006). We placed these 14 common genes in an 'Agreed set' and a genome with these genes

157 removed was also simulated.

159 We simulated each minimal gene set in the M. genitalium whole-cell model and found that

160 every set, including the Agreed set, produced a non-dividing in-silico cell (30 in-silico replicates,

161 Supplementary Data 5).

163 Analysis found that every one of the sets deleted essential genes (classified in-silico previously

164 (Karr et al., 2012; Rees-Garbutt et al., 2020)): Nashville deleted 121, Fujisawa deleted 112,

165 Guelph deleted 107, Valencia deleted 69, Bethesda deleted 34, Rockville and Rockville 2 both

166 deleted 9, and Stanford deleted 3 (Supplementary Data 6-14). This is especially surprising for

167 the single gene essentiality minimal gene sets. For the Rockville sets, this is likely due to

168 transposon mutagenesis issues. Rockville labelled six genes as non-essential in 1999,

169 subsequently labelled essential in 2006. Additionally, Rockville grew cells in mixed pools with

170 DNA isolated from these mixtures rather than from isolated pure colonies of cells (J. I. Glass et 
171 al., 2006). Whereas for Rockville 2, the engineers of JCVI-Syn3.0 used the same transposon

172 mutagenesis protocol (Hutchison et al., 2016), but found that they had to improve upon it due

173 to incorrect identification of essentiality. For the Stanford set, the removal of MG_203, MG_250,

174 and MG_470 is likely due to averaging multiple simulation's data together before computational

175 assessment, genes later found to be essential (Supplementary Table 3(Rees-Garbutt et al.,

176 2020)).

178 In an attempt to restore in-silico division, we reintroduced essential genes to the minimal gene

179 sets (Figure 1). Based on previous research (Rees-Garbutt et al., 2020), we also reintroduced

180 low essential genes (i.e. genes dispensable in some contexts, such as redundant essential

181 genes and gene complexes (Rancati et al., 2018)). We did this by comparing the gene content

182 of the individual minimal gene sets with a complete list of the M. genitalium in-silico genes and

183 their essentiality classifications (Rees-Garbutt et al., 2020) (Supplementary Data 6-14). For

184 example, the original Agreed set removed low essential genes MG_291 (phosphonate

185 transport) and MG_412 (phosphate transport); by disrupting both these processes, the in-silico

186 cell has no functioning source of phosphate, which has been established previously

187 (Rees-Garbutt et al., 2020). By reintroducing set-specific genes (Table 2, Supplementary Data

188 15), each modified set, including the Agreed set, was able to produce a dividing cell in-silico (30

189 in-silico replicates, Supplementary Data 5). 
191 Figure 1. Testing and restoring the minimal gene sets.
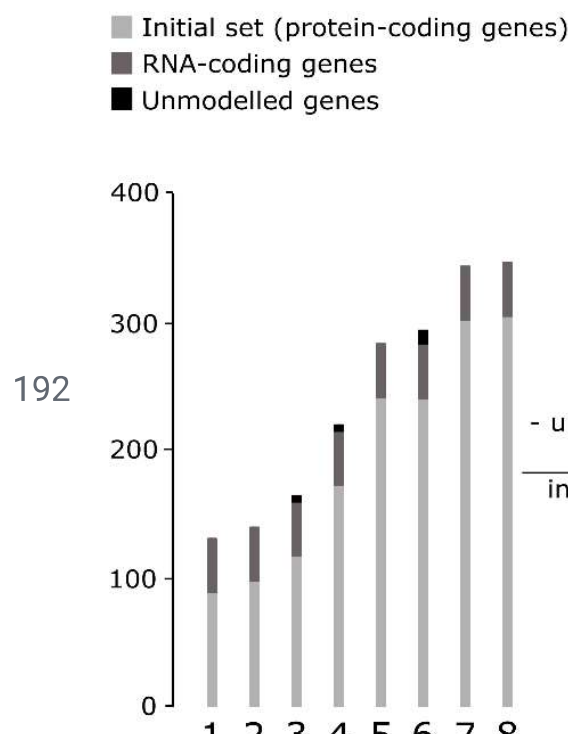

12345678 
199 Table 2. Reintroducing genes to produce division

\begin{tabular}{|c|c|c|c|c|c|}
\hline $\begin{array}{c}\text { Code } \\
\text { name }\end{array}$ & $\begin{array}{c}\text { In-silico gene } \\
\text { deletions } \\
\text { (cell did not divide) }\end{array}$ & $\begin{array}{c}\text { In-silico gene } \\
\text { deletions } \\
\text { (cell divided) }\end{array}$ & $\begin{array}{c}\text { Essential genes } \\
\text { reintroduced }\end{array}$ & $\begin{array}{c}\text { Low essential } \\
\text { genes } \\
\text { reintroduced }\end{array}$ & $\begin{array}{c}\text { Size of in-silico } \\
\text { genome * }\end{array}$ \\
\hline Nashville & 270 & 142 & 121 & 7 & 259 \\
\hline Fujisawa & 261 & 142 & 112 & 7 & 259 \\
\hline Guelph & 241 & 128 & 107 & 6 & 273 \\
\hline Valencia & 185 & 110 & 69 & 6 & 291 \\
\hline Stanford & 117 & 82 & 3 & 5 & 319 \\
\hline Bethesda & 118 & 45 & 9 & 2 & 356 \\
\hline Rockville 2 & 57 & 43 & 9 & 3 & 358 \\
\hline Rockville & 53 & 13 & 0 & 1 & 388 \\
\hline Agreed & 14 & & & & 29 \\
\hline
\end{tabular}

201 Minimal gene sets before and after the reintroduction of essential and low essential genes

202 dividing in-silico cells. *Size of in-silico genome includes both the 359 protein-coding genes and

203 the 42 RNA-coding genes in the M. genitalium whole-cell model, to provide a better

204 comparison for in-vivo experiments and future work.

206 In an attempt to gain further understanding, we investigated what processes the nine repaired

207 minimal gene sets removed using gene ontology (GO) biological process terms, and we

208 compared the repaired minimal gene sets to the in-silico M. genitalium minimal genomes we

209 produced previously (Rees-Garbutt et al., 2020). The smallest repaired in-silico genomes

210 (Nashville and Fujisawa, 259 genes) were larger than the prior novel in-silico minimal genomes

211 (256 and 237 genes), and both removed the low essential genes related to phosphonate

212 transport, relying on inorganic phosphate being transported into the cell (Supplementary Table

213 6(Rees-Garbutt et al., 2020)). The other sets had different designs that, due to not

214 systematically targeting non-essential genes, resulted in non-essential genes remaining in the

215 genome, making them subsets of the repaired protocell sets and the prior in-silico minimal 
216 genomes (Supplementary Data 16). As such, the GO terms were also subsets and did not

217 deviate from what we would expect to produce a dividing in-silico cell (Supplementary Data

218 17-25)

220 Analysis of the repaired sets found that 31 genes were reintroduced into five or more of the

221 minimal gene sets (Supplementary Data 26). 26 were essential and 5 were low essential

222 (Supplementary Table 5(Rees-Garbutt et al., 2020)). The corresponding cellular functions

223 included: DNA (polymerase subunits, thymidine insertion, recycling of pyrimidine, chromosome

224 segregation); RNA (polymerase subunit, tRNA modification, the $50 S$ and $30 S$ ribosomal

225 subunits); transporters (cobalt, phosphonate, potassium); production (NAD, flavin, NADP, fatty

226 acid/phospholipids); and dehydrogenation (glycerol and alpha-keto acids). Of the 26

227 reintroduced essential genes, 19 were already present in the single gene deletion minimal gene

228 sets (Stanford, Rockville, Rockville 2). MG_137 (mycobacteria cell wall production) and MG_517

229 (plasma membrane stability) are genes specifically essential for Mycoplasma species, which

230 were only identified as essential by the single gene deletion minimal gene sets. A further five

231 genes were involved in cobalt transport, which increases the rates of DNA synthesis, fatty acid

232 metabolism, and amino acid metabolism, and were also not identified as essential by the other

233 design methodologies. Of the five reintroduced low essential genes, Bethesda did not delete

234 four, likely due to the direct comparison of two genomes resulting in low essentiality genes

235 being conserved to a greater degree.

237 We also looked at reintroductions to the protocell sets, as they could outline additional cellular

238 requirements for the successful future unification of independent protocell systems. The genes

239 reintroduced to the Nashville set repaired functions that had been reduced (translation,

240 glycolytic process, protein folding) and restored functions that had been removed including: cell 
241 (division, cycle, transport, redox homeostasis), DNA (topological change, transcription), rRNA

242 processing (including pseudouridine synthesis), protein transport, and cellular processes

243 (carbohydrate metabolic, glycerol metabolic, fatty acid biosynthesis, UMP salvage)

244 (Supplementary Data 27). The glycolytic process had the most change, with 10 of 11 genes

245 being reintroduced, and DNA repair had the least, with only one gene being reintroduced

246 (MG_254), however, this did reintroduce single strand DNA break repair. The genes additionally

247 reintroduced to the Fujisawa set included tRNA processing and protein folding (Supplementary

248 Data 28), with 8 out of 10 DNA replication genes reintroduced.

\section{Discussion}

251 In conclusion, the repaired protocell minimal gene sets (Nashville and Fujisawa) produced the

252 smallest genomes in-silico (Table 2), differing by 6 genes (Supplementary Data 29), but required

253 the most gene reintroductions. The repaired comparative genomics minimal gene sets (Guelph,

254 Valencia, Bethesda) required fewer gene reintroductions, presumably because fewer genomes

255 were compared during their original design. Interestingly, Stanford (a single gene essentiality

256 set) produced a smaller in-silico genome than Bethesda (a comparative genomics set), as it did

257 not target unmodelled gene deletions and only required eight genes to be reintroduced.

259 This research has limitations associated with the use of the M. genitalium whole-cell model.

260 Through necessity the M. genitalium whole-cell model bases some of its parameters on data

261 from other bacteria ${ }^{8}$ and is only capable of modelling a single generation, missing

262 subgenerational gene expression and subsequent essentiality which affects $>50 \%$ of the genes

263 in some species (Macklin et al., 2020). Additional uncertainty exists around the unknown impact

264 of the unmodelled genes on in-vivo experiments, as stated previously (Rees-Garbutt et al.,

265 2020). 
266 The computational predictions we have produced need to be tested in living cells, but with the

267 advancement of gene synthesis and genome transplantation in other Mycoplasma species

268 (Benders et al., 2010; Gibson, Benders, Andrews-Pfannkoch, et al., 2008; Gibson, Benders,

269 Axelrod, et al., 2008; Gibson et al., 2010; Karas et al., 2013; Tsarmpopoulos et al., 2016) this is

270 becoming a more realistic proposition for Mycoplasma researchers.

272 Without the ability to identify species-specific low essential genes, any minimal gene sets

273 designed with the current incomplete and fragmented gene essentiality information will require

274 gene reintroductions to produce dividing cells. New research is required to generate the

275 knowledge required to fill these gaps. Currently, genome-scale engineering has not combined

276 in silico and in vivo research (Jiang et al., 2013; Karr et al., 2012; Rees-Garbutt et al., 2020).

277 With the recent publication of an E.coli whole-cell model (Macklin et al., 2020) and the

278 introduction of a synthetic, recoded E.coli genome into a cell (Fredens et al., 2019), this will

279 quickly change. The current nature of species-specific gene essentiality information is,

280 potentially, the only remaining barrier to producing custom genomes. 


\section{Methods}

283 These methods have been published previously [27].

Experimental Design and Statistics

286 Each simulation was replicated 30 times. Prior publications have completed five repetitions [8],

287 ten or one hundred repetitions [27], depending on data storage capacity and supercomputer

288 usage. These were the main factors in our choice for the number of replications.

289 The initial conditions for each simulation are randomised within a natural range for $M$. genitalium

290 cells, introducing variation in the behaviour of simulated cells [8], as previously shown [27].

291 Statistical tests were not used in this research.

292

\section{Code Availability}

294 All code created as part of this paper will be made available on Github under a GNU General

295 Public License v3.0 (gpl-3.0). For more information see choosealicense.com/licenses/lgpl-3.0/.

297 Data Availability

298 The databases used to design the in-silico experiments, and compare the results to, includes

299 Karr et al. (Karr et al., 2012) and Glass et al. (J. I. Glass et al., 2006) Supplementary Tables, and

300 Fraser et al. M. genitalium G37 genome (Fraser et al., 1995) interpreted by KEGG (Kanehisa \&

301 Goto, 2000) and UniProt (Apweiler et al., 2004) as strain ATCC 33530/NCTC 10195. The output

302 .fig files for all simulations referenced will be made available at the group's Research Data

303 Repository (data-bris) at the University of Bristol. 


\section{Model Availability}

306 The M. genitalium whole-cell model is freely available: github.com/CovertLab/WholeCell. The

307 model requires a single CPU and can be run with 8GB of RAM. We run the $M$. genitalium

308 whole-cell model on Bristol's supercomputers using MATLAB R2013b, with the model's

309 standard settings. However, we use our own version of the SimulationRunner.m.

310 MGGRunner.m

311 (github.com/GriersonMarucciLab/Analysis_Code_for_Mycoplasma_genitalium_whole-cell_mod

$312 \mathrm{el})$ is designed for use with supercomputers that start hundreds of simulations simultaneously. It

313 artificially increments the starting time-date value for each simulation, as this value is

314 subsequently used to create the initial conditions of the simulation. Our research copy of the

315 whole-cell model was downloaded 10th January 2017.

317 M. genitalium in-silico Environmental Conditions

318 M. genitalium is grown in-vivo on SP4 media. The in-silico media composition is based on the

319 experimentally characterized composition, with additional essential molecules added

320 (nucleobases, gases, polyamines, vitamins, and ions) in reported amounts to support in-silico

321 cellular growth. Additionally, the M. genitalium whole-cell model represents 10 external stimuli

322 including temperature, several types of radiation, and three stress conditions. For more

323 information see Karr et al. Supplementary Tables S3F, S3H, S3R (Karr et al., 2012).

325 Equipment

326 For the M. genitalium whole-cell model we used the University of Bristol Advanced Computing

327 Research Centres's BlueGem, a 900-core supercomputer, which uses the Slurm queuing

328 system, to run whole-cell model simulations. 
329 We used a standard office desktop computer, with 8GB of ram, to write new code, and interact

330 with the supercomputer. We used the following GUI software on Windows 7: Notepad++ for

331 code editing, Putty (ssh software) for terminal access to the supercomputer, FileZilla (ftp

332 software) to move files in bulk to and from the supercomputer, and PyCharm (IDE software) as

333 an inbuilt desktop terminal and for python debugging. The command line software used

334 included: VIM for code editing, and SSH, Rsync, and Bash for communication and file transfer

335 with the supercomputers.

337 Data Format

338 For the M. genitalium whole-cell model the majority of output files are state-NNN.mat files,

339 which are logs of the simulation split into 100-second segments. The data within a

340 state-NNN.mat file is organised into the 16 cellular variables. These are typically arranged as

341 3-dimensional matrices or time series, which are flattened to conduct analysis. The other file

342 types contain summaries of data spanning the simulation. Each gene manipulated simulation

343 can consist of up to 500 files requiring between $0.4 \mathrm{~GB}$ and $0.9 \mathrm{~GB}$. Each simulation takes 5 to

34412 hours to complete in real time, 7 - 13.89 hours in simulated time.

346 Data Analysis Process

347 For the $M$. genitalium whole-cell model, the raw data is automatically processed as the

348 simulation ends. runGraphs.m carries out the initial analysis, while compareGraphs.m overlays

349 the output on collated graphs of 200 unmodified M. genitalium simulations. Both outputs are

350 saved as MATLAB .fig and .pdfs, though the .pdf files were the sole files analysed. The raw

351 .mat files were stored in case of further investigation. 
353 The GO biological process terms used for further analysis were downloaded from Uniprot

354 (Apweiler et al., 2004) (strain ATCC 33530/NCTC 10195), processed by a created script

355 (github.com/squishybinary/Gene_Ontology_Comparison_for_Mycoplasma_genitalium_whole-ce

356 II_model) in combination with lists of genes, organised manually into tables of GO terms that

357 were unaffected, reduced, or removed entirely by gene deletions, and then analysed.

\section{Modelling Scripts}

360 There are six scripts used to run the $M$. genitalium whole-cell model. Three are the experimental

361 files created with each new experiment (the bash script, gene list, experiment list), and three are

362 stored within the whole-cell model and are updated only upon improvement (MGGrunner.m,

363 runGraphs.m, and compareGraphs.m). The bash script is a list of commands for the

364 supercomputer(s) to carry out. Each bash script determines how many simulations to run,

365 where to store the output, and where to store the results of the analysis. The gene list is a text

366 file containing rows of gene codes (in the format ' $M G_{-} X X X$ ',). Each row corresponds to a single

367 simulation and determines which genes that simulation should knockout. The experiment list is

368 a text file containing rows of simulation names. Each row corresponds to a single simulation

369 and determines the final location of the simulation output and analysis results. 


\section{Acknowledgements}

372 We thank the Advanced Computing Research Centre (ACRC) and BrisSynBio, a

373 BBSRC/EPSRC Synthetic Biology Research Centre, at the University of Bristol for access to the

374 Bluegem supercomputer.

375

376 Competing Interests

377 The authors declare no competing interests.

\section{Funding}

380 J.R-G. was supported by BrisSynBio, a BBSRC/EPSRC Synthetic Biology Research Centre

381 (BB/L01386X/1), with a funded PDRA position and research grant. L.M. was supported by the

382 Engineering and Physical Sciences Research Council (grant EP/S01876X/1) and by the

383 European Union's Horizon 2020 research and innovation programme (grant agreement

384 766840). L.M. and C.G. were supported by a BrisSynBio (BB/L01386X/1) flexi-fund grant.

385 O.C. was supported by the Bristol Centre for Complexity Sciences (BCCS) Centre for Doctoral

386 Training (CDT) EP/I013717/1.

388 Author Contributions

389 C.G., L.M., O.C., J.R-G were involved in ideation. O.C. conducted simulations comparing the

390 Stanford and Rockville 2 sets, a prototype version of the research presented here. J.R-G.

391 collated, simulated, analysed and repaired the nine sets, and wrote the paper and

392 supplementary data 1 - 16, 26 - 29. J.R. analysed the nine sets and wrote supplementary data

39317 - 25. C.G. and L.M supervised the project. C.G., L.M., J.R. edited the paper. 


\section{References}

396 Apweiler, R., Bairoch, A., Wu, C. H., Barker, W. C., Boeckmann, B., Ferro, S., Gasteiger, E., Huang, H., Lopez, R., Magrane, M., Martin, M. J., Natale, D. A., O’Donovan, C., Redaschi, N., \& Yeh, L.-S. L. (2004). UniProt: the Universal Protein knowledgebase. Nucleic Acids Research, 32(Database issue), D115-D119.

400 Benders, G. A., Noskov, V. N., Denisova, E. A., Lartigue, C., Gibson, D. G., Assad-Garcia, N., Chuang, R. Y., Carrera, W., Moodie, M., Algire, M. A., Phan, Q., Alperovich, N., Vashee, S., Merryman, C., Venter, J. C., Smith, H. O., Glass, J. I., \& Hutchison, C. A. (2010). Cloning whole bacterial genomes in yeast. Nucleic Acids Research, 38(8), 2558-2569. du Plessis, D. J. F., Nouwen, N., \& Driessen, A. J. M. (2011). The Sec translocase. Biochimica et Biophysica Acta, 1808(3), 851-865.

Dzieciol, A. J., \& Mann, S. (2012). Designs for life: protocell models in the laboratory. Chemical Society Reviews, 41(1), 79-85.

408 Fleischmann, R. D., Adams, M. D., White, O., Clayton, R. A., Kirkness, E. F., Kerlavage, A. R., Bult, C. J., Tomb, J. F., Dougherty, B. A., \& Merrick, J. M. (1995). Whole-genome random sequencing and assembly of Haemophilus influenzae Rd. Science, 269(5223), 496-512.

411 Forster, A. C., \& Church, G. M. (2006). Towards synthesis of a minimal cell. Molecular Systems

413 Fraser, C. M., Gocayne, J. D., White, O., Adams, M. D., Clayton, R. A., Fleischmann, R. D., 414 Bult, C. J., Kerlavage, A. R., Sutton, G., Kelley, J. M., Fritchman, J. L., Weidman, J. F., 415 Small, K. V., Sandusky, M., Fuhrmann, J., Nguyen, D., Utterback, T. R., Saudek, D. M., 416 Phillips, C. A., ... Venter, J. C. (1995). The Minimal Gene Complement of 417 Mycoplasma-genitalium. Science, 270(5235), 397-403.

418 Fredens, J., Wang, K., de la Torre, D., Funke, L. F. H., Robertson, W. E., Christova, Y., Chia, T., 419 Schmied, W. H., Dunkelmann, D. L., Beránek, V., Uttamapinant, C., Llamazares, A. G., 

genome. Nature, 569(7757), 514-518. Complete chemical synthesis, assembly, and cloning of a Mycoplasma genitalium genome. Science, 319(5867), 1215-1220.

Gibson, D. G., Benders, G. A., Axelrod, K. C., Zaveri, J., Algire, M. A., Moodie, M., Montague, M. G., Venter, J. C., Smith, H. O., \& Hutchison, C. A. (2008). One-step assembly in yeast of 25 overlapping DNA fragments to form a complete synthetic Mycoplasma genitalium genome. Proceedings of the National Academy of Sciences of the United States of America, 105(51), 20404-20409.

Gibson, D. G., Glass, J. I., Lartigue, C., Noskov, V. N., Chuang, R. Y., Algire, M. A., Benders, G. A., Montague, M. G., Ma, L., Moodie, M. M., Merryman, C., Vashee, S., Krishnakumar, R., Assad-Garcia, N., Andrews-Pfannkoch, C., Denisova, E. A., Young, L., Qi, Z. Q., Segall-Shapiro, T. H., ... Venter, J. C. (2010). Creation of a Bacterial Cell Controlled by a

Gil, R. (2015). The Minimal Gene-Set Machinery. In R. A. Meyers (Ed.), Synthetic Biology (pp. 443-478). John Wiley \& Sons. bacterial gene set. Microbiology and Molecular Biology Reviews: MMBR, 68(3), 518 - +.

441 Glass, J. I., Assad-Garcia, N., Alperovich, N., Yooseph, S., Lewis, M. R., Maruf, M., Hutchison, 442 C. A., Smith, H. O., \& Venter, J. C. (2006). Essential genes of a minimal bacterium. Proceedings of the National Academy of Sciences of the United States of America, 103(2), 425-430. 
445 Glass, J. I., Merryman, C., Wise, K. S., Hutchison, C. A., 3rd, \& Smith, H. O. (2017). Minimal

$446 \quad$ Cells-Real and Imagined. Cold Spring Harbor Perspectives in Biology.

448 Huang, C. H., Hsiang, T., \& Trevors, J. T. (2013). Comparative bacterial genomics: defining the 449 minimal core genome. Antonie Van Leeuwenhoek International Journal of General and $450 \quad$ Molecular Microbiology, 103(2), 385-398.

451 Hutchison, C. A., Chuang, R. Y., Noskov, V. N., Assad-Garcia, N., Deerinck, T. J., Ellisman, M.

452 H., Gill, J., Kannan, K., Karas, B. J., Ma, L., Pelletier, J. F., Qi, Z. Q., Richter, R. A., 453 Strychalski, E. A., Sun, L. J., Suzuki, Y., Tsvetanova, B., Wise, K. S., Smith, H. O., ... 454 Venter, J. C. (2016). Design and synthesis of a minimal bacterial genome. Science, 351(6280), 1414-U73.

456 Hutchison, C. A., Peterson, S. N., Gill, S. R., Cline, R. T., White, O., Fraser, C. M., Smith, H. O., 457 \& Venter, J. C. (1999). Global transposon mutagenesis and a minimal mycoplasma genome. Science, 286(5447), 2165-2169.

459 Jiang, W. Y., Bikard, D., Cox, D., Zhang, F., \& Marraffini, L. A. (2013). RNA-guided editing of 460 bacterial genomes using CRISPR-Cas systems. Nature Biotechnology, 31(3), 233-239.

461 Juhas, M., Eberl, L., \& Glass, J. I. (2011). Essence of life: essential genes of minimal genomes. 462 Trends in Cell Biology, 21(10), 562-568.

463 Kanehisa, M., \& Goto, S. (2000). KEGG: kyoto encyclopedia of genes and genomes. Nucleic Acids Research, 28(1), 27-30.

465 Karas, B. J., Jablanovic, J., Sun, L. J., Ma, L., Goldgof, G. M., Stam, J., Ramon, A., Manary, 466 M. J., Winzeler, E. A., Venter, J. C., Weyman, P. D., Gibson, D. G., Glass, J. I., Hutchison, 467 C. A., Smith, H. O., \& Suzuki, Y. (2013). Direct transfer of whole genomes from bacteria to yeast. Nature Methods, 10(5), $410-+$.

469 Karr, J. R., Sanghvi, J. C., Macklin, D. N., Gutschow, M. V., Jacobs, J. M., Bolival, B., Jr, 
472 Kazakiewicz, D., Karr, J. R., Langner, K. M., \& Plewczynski, D. (2015). A combined systems

473 and structural modeling approach repositions antibiotics for Mycoplasma genitalium.

474 Computational Biology and Chemistry, 59 Pt B, 91-97.

475 Koonin, E. V. (2003). Comparative genomics, minimal gene-sets and the last universal common 476 ancestor. Nature Reviews. Microbiology, 1(2), 127-136.

477 Lagesen, K., Ussery, D. W., \& Wassenaar, T. M. (2010). Genome update: the 1000th genome 478 a cautionary tale. Microbiology-Sgm, 156, 603-608.

479 Macklin, D. N., Ahn-Horst, T. A., Choi, H., Ruggero, N. A., Carrera, J., Mason, J. C., Sun, G., 480 Agmon, E., DeFelice, M. M., Maayan, I., Lane, K., Spangler, R. K., Gillies, T. E., Paull, M. 481 L., Akhter, S., Bray, S. R., Weaver, D. S., Keseler, I. M., Karp, P. D., .. Covert, M. W. 482 (2020). Simultaneous cross-evaluation of heterogeneous E. coli datasets via mechanistic simulation. Science, 369(6502). https://doi.org/10.1126/science.aav3751

484 Mushegian, A. R., \& Koonin, E. V. (1996). A minimal gene set for cellular life derived by comparison of complete bacterial genomes. Proceedings of the National Academy of Sciences of the United States of America, 93(19), 10268-10273.

487 Purcell, O., Jain, B., Karr, J. R., Covert, M. W., \& Lu, T. K. (2013). Towards a whole-cell 488 modeling approach for synthetic biology. Chaos , 23(2), 025112.

489 Rancati, G., Moffat, J., Typas, A., \& Pavelka, N. (2018). Emerging and evolving concepts in 490 gene essentiality. Nature Reviews. Genetics, 19(1), 34-49.

491 Rees-Garbutt, J., Chalkley, O., Landon, S., Purcell, O., Marucci, L., \& Grierson, C. (2020). 492 Designing minimal genomes using whole-cell models. Nature Communications, 11(1), 836. 493 Reich, K. A. (2000). The search for essential genes. Research in Microbiology, 151(5), 319-324. 494 Sanghvi, J. C., Regot, S., Carrasco, S., Karr, J. R., Gutschow, M. V., Bolival, B., Jr, \& Covert, 

1192-1195.

497 Shuler, M. L., Foley, P., \& Atlas, J. (2012). Modeling a Minimal Cell. In A. Navid (Ed.), Microbial 498 Systems Biology (Vol. 881, pp. 573-610). Humana Press.

499 Tomita, M., Hashimoto, K., Takahashi, K., Shimizu, T. S., Matsuzaki, Y., Miyoshi, F., Saito, K.,

500 Tanida, S., Yugi, K., Venter, J. C., \& Hutchison, C. A. (1999). E-CELL: software

501 environment for whole-cell simulation. Bioinformatics , 15(1), 72-84.

502 Tsarmpopoulos, I., Gourgues, G., Blanchard, A., Vashee, S., Jores, J., Lartigue, C., \&

503 Sirand-Pugnet, P. (2016). In-Yeast Engineering of a Bacterial Genome Using CRISPR/Cas9.

504 ACS Synthetic Biology, 5(1), 104-109. 